\title{
Curcumin supplementation in the treatment of patients with cancer: a systematic review
}

\author{
Taise Andrade da Anunciação ${ }^{\circledR 1}$, Laís Spindola Garcez ${ }^{1}$, \\ Emile Miranda Pereira1, Valterlinda Alves de Oliveira Queiroz ${ }^{1}$, \\ Priscila Ribas de Farias Costa ${ }^{1}$, Lucivalda Pereira Magalhães de Oliveira ${ }^{1}$ \\ ${ }^{1}$ School of Nutrition, Federal University of Bahia, Salvador, Bahia, Brazil
}

\begin{abstract}
Feeding with high levels of phytochemicals, including curcumin, may be a therapeutic option for diseases such as cancer which is a public health problem. The aim of this study was to systematically review the results of clinical trials investigating the effect of oral curcumin supplementation on anti-inflammatory and antioxidant profiles, reduction of PSA levels and degree of dermatitis in radiotherapy treatment in cancer patients. The review was carried out based on the items of the PRISMA Statement. A bias risk assessment was performed according to Cochrane Collaboration criteria. Six studies met the eligibility criteria and were included in the systematic review. The results of this study are based on those obtained in the literature on the effect of curcumin on the anti-inflammatory profile, on reducing dermatitis, on PSA alteration and on anti-oxidant profile for a total of 450 individuals, comprising 259 in the intervention group and 191 in the control group. Some studies have reported improvement in biochemical and clinical indicators, with limited adverse effects and good tolerance. It was not possible to determine, with the desired degree of evidence, the effect of curcumin supplementation in the treatment of cancer patients. It is important to consider the great heterogeneity and methodological weaknesses of the studies, and that it was not possible to perform a meta-analysis of the data available in the literature.
\end{abstract}

Keywords: Curcumin. Cancer. Systematic review. Anti-inflammatory profile. Anti-oxidant profile.

\section{INTRODUCTION}

Studies published to date have shown that feeding with high levels of dietary fibers, vitamins, minerals and polyphenols confers a protective role for a number of chronic diseases, including cancer (CA) (Ferlay et al., 2015; Tachibana, 2011). The anti-inflammatory and immunomodulator effects of phytochemicals, such as curcumin, may serve as an important complementary therapeutic option in the treatment of these patients (Rezaee et al., 2017).

Curcumin is a long-used phytochemical with a large number of biological targets, for which antiinflammatory, antioxidant, anti-tumor, immunoregulatory, hepatoprotective, anti-ischemic, anti-dyspeptic, anti-

*Correspondence: T. A. da Anunciação. Faculdade de Nutrição. Universidade Federal da Bahia. Rua Basílio da Gama, s/n Canela, CEP 40110-907 - Salvador, Bahia, Brasil - Phone: (55) 713283 7719. E-mail: tai. anunciacao@hotmail.com depressant, and analgesic effects have been determined (Amalraj et al., 2017).

Preclinical studies have reported curcumin as a potent epigenetic regulator, acting in the inhibition of deoxyribonucleic acid (DNA), DNA methyltransferases (DNMTs), regulation of modifications of histone acetyltransferases (HATs) and deacetylases (HDACs) and in regulation of micro ribonucleic acids (miRNA) (Boyanapalli et al., 2015; Remely et al., 2015). Studies conducted in vitro show that curcumin prevents the degradation of nuclear factor erythroid 2-related factor 2 (Nrf2), leading to an increase in antioxidant enzymes such as superoxide dismutase (SOD), catalase and glutathione peroxidase (GPx). In addition, it balances the level of these enzymes and recovers reactive oxygen species (Rezaee et al., 2017; Sahebkar, 2013). It was also shown to have an anti-inflammatory effect through negative regulation of several cytokines, such as tumor necrosis factor alpha (TNF- $\alpha$ ), interleukins (IL-1, IL- 
6, IL-8, IL-12), monocyte chemoattractant protein-1, cyclooxygenase-2 activity (COX-2), lipoxygenase enzyme and inducible nitric oxide synthase (iNOS) (Aggarwal et al., 2007; Gupta et al., 2013).

In vitro and in vivo investigations have also shown that curcumin reduces the inflammatory process by means of inflammatory transcription factors such as nuclear factor kappa (NF-kB), activator protein-1 (AP1) and signal transducer and activator of transcription 3 (STAT3) (Panda et al., 2017; Imran et al., 2016). NF-кB and AP-1 also act as transcription factors that regulate the expression of different genes which affect cellular processes, such as proliferation and apoptosis. Curcumin also inhibited the expression of urokinase plasminogen (uPA), focal adhesion kinase activity (FAK), suppressed expression of matrix metalloproteinases (MMPs), inhibited epidermal growth factor receptor (EGFR) activity, regulating tumor cell invasion and metastasis (Durgaprasad et al., 2005; Vadhan-Raj et al., 2007; Kim et al., 2011; Belcaro et al., 2010; Shokes et al., 2005; Adhvaryu et al., 2008; Biswas et al., 2010). Due to these therapeutic properties, curcumin exhibited activities against various types of CA (Gupta et al., 2013; Dhillon et al., 2008; Golombick et al., 2009; Ide et al., 2010). The main molecular targets and mechanisms of action of curcumin are summarized in Figure 1.

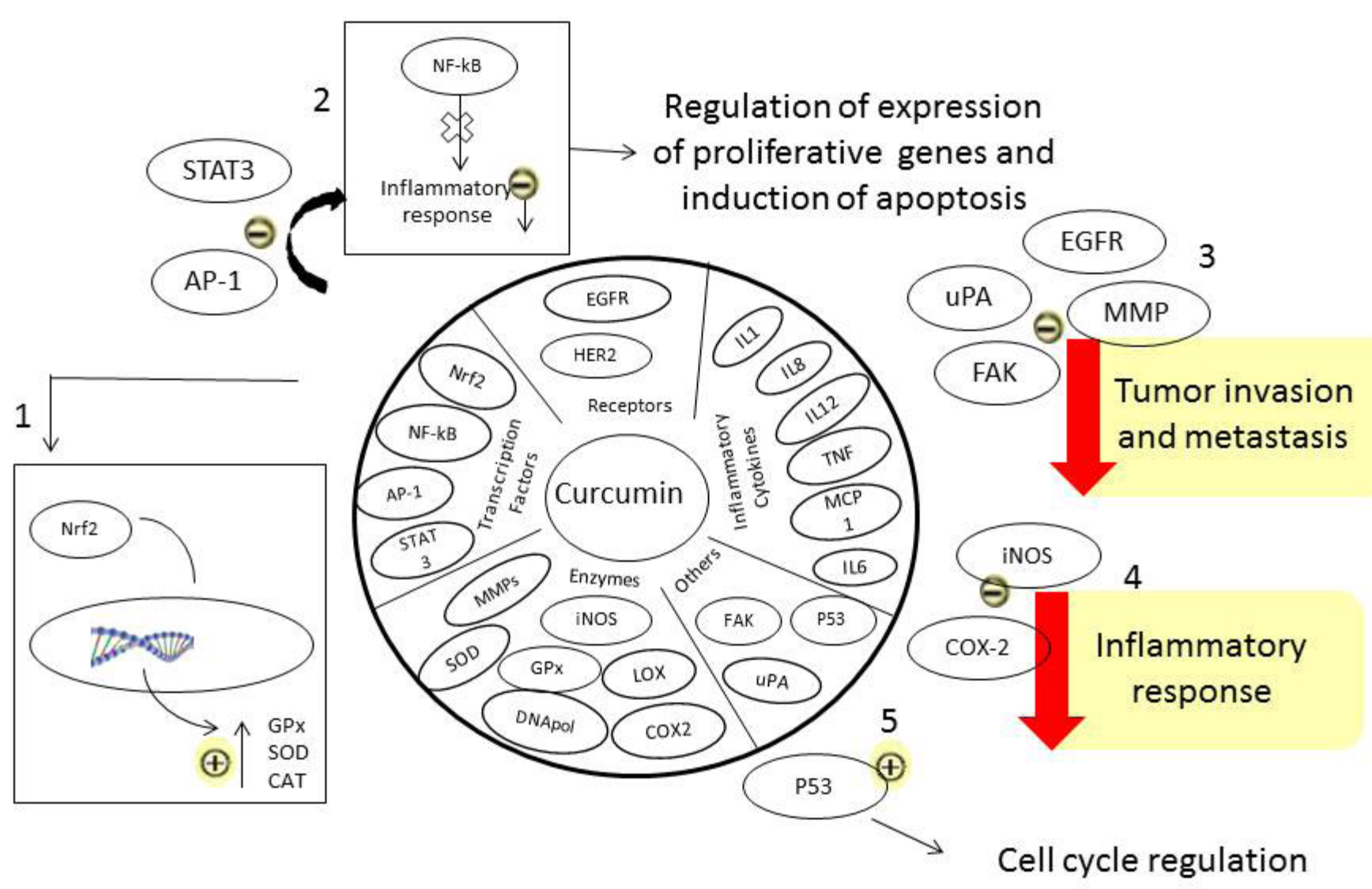

FIGURE 1 - Molecular targets and possible mechanisms of action of curcumin. Adapted from Kunnumakkara et al. (2017) AP-1: Activating Protein-11; COX-2: Cyclooxygenase-2; DNA Deoxyribonucleic Acid; DNA Pol: DNA polymerase; EGF: Epidermal growth factor; FAK: Focal adhesion kinase; GST: Glutathione-S-transferase; HER-2: Human epidermal growth factor receptor 2; IL-1: Interleukin-1; IL-6: Interleukin-6; IL-8: Interleukin-8; IL-12: Interleukin-12; iNOS: Inducible Nitric Oxide Synthase; MCP: Monocyte chemoattractant protein; MMP: matrix metalloproteinase; Nrf2: nuclear factor-erythroid 2related factor 2; STAT-3: Signal transducer and activator of transcription 3; TNF: Tumor necrosis factor alpha; uPA: Urokinase plasminogen activator. 1 - Curcumin prevents degradation of Nrf2 which leads to an increase in antioxidant enzymes. 2 Inhibits activation of NF-kB, reducing the inflammatory response, and also inhibits activation of AP-1 and STAT3 by regulating the expression of proliferative genes and inducing apoptosis. 3 - Inhibition of uPA, EGFR, FAK, and MMP leads to air invasion and metastasis of the tumor. 4 - Inhibits iNOS and COX-2, reducing the inflammatory response. 5 - Activates the P53 protein responsible for cell cycle regulation. 
However, there is no consensus among specialists on the use of curcumin as a coadjuvant in the clinical treatment of patients with CA. Results of clinical trials are conflicting due to a lack of standardization of methodological aspects, with differences in concentration, type of active principles and intervention time length. Given this scenario, the aim of the present study was to systematically review the results of clinical trials investigating the effect of oral curcumin supplementation in the treatment of patients with CA on antiinflammatory profile, antioxidant activity, decrease in prostatespecific antigen (PSA) levels, and degree of dermatitis in radiotherapy treatment.

\section{MATERIAL AND METHODS}

\section{Search strategy}

A systematic review of randomized and controlled clinical trials in adult and elderly patients with CA was performed according to recommendations of the Preferred Reporting Items for Systematic Reviews and MetaAnalyses: the PRISMA Statement (Moher et al., 2009).

The databases Medline/Pubmed, Embase, Cochrane Central Register of Controlled Trials were used in the Cochrane Library, Lilacs, and Clinical Trials. The search was carried out from July 01 to August 31, 2017. The construction of the search strategy was based on the structured PICO process - Population, Intervention, Comparison, Outcome. We used the terms indexed for CA and curcumin, according to the terminology adopted by the site of the Descriptors in Sciences and Health (DeCS), Medical Subject Headings (MeSH) and Embase Subject Headings (Emtree), combined using the Boolean operators "OR" and "AND", without restriction of geographical area, language or year of publication. The terms of outcome were not defined so as to avoid assigning undesirable specificity at this collection stage (Brazil, 2012).

\section{Selection of studies}

Two independent reviewers selected randomized and controlled clinical trials including adult and elderly patients with CA of both sexes, who adopted oral use of curcumin in the form of extract, capsule or powder, alone or in combination with other nutrients, collecting information regarding the intervention, such as dose, frequency, duration of intervention and details of the product used. For inclusion, studies also had to present information regarding the anti-inflammatory profile, through interleukins (IL-6, IL-8, IL-10, IL-1), C-reactive protein (CRP) and TNF- $\alpha$; antioxidant activity, through antioxidant enzymes (catalase, SOD, GPx) and reactive oxygen species; prostate-specific antigen (PSA); and degree of dermatitis associated with anti-neoplastic treatment. We excluded studies involving children, adolescents, review studies, non-randomized, editorial, in vitro or in vivo model studies. Review articles were used to identify possible additional relevant studies not retrieved by the search strategy.

The selection of studies began independently, by screening titles and abstracts, with subsequent reading of the full texts. Disagreements between the reviewers regarding the eligibility of the articles were resolved by a third reviewer. The data were extracted from the eligible studies independently by the two reviewers using a standard clinical record for data collection of the variables of interest, including information about participants/ population, intervention, methods/study design, outcomes, and results, based on the Cochrane Group criteria. In the case of incomplete data, such as the absence of baseline and/or post-intervention data, authors of the articles were contacted via e-mail to obtain information about their studies.

\section{Evaluation of study quality}

Eligible studies were analyzed by two external evaluators, according to an instrument recommended by the Cochrane Collaboration for randomized studies, which included identification of selection bias, performance bias, detection bias, friction bias, and reporting bias (Higgins et al., 2011; Carvalho et al., 2013). Discrepancies were resolved by a third evaluator. Data analysis was performed using Revman 5.3 software (Cochrane IMS, Oxford, UK).

\section{Difference between Protocol and Systematic Review}

The protocol of initial research, registered in the International Prospective Register of Systematic Reviews (PROSPERO: CRD42017071650), included performing a meta-analysis, however, this step was not possible due to the insufficient number of studies with the same outcome, different scales in data presentation, great heterogeneity and methodological weakness of the studies. Therefore, the studies identified in the systematic review proved insufficient to perform a meta-analysis on the research question. 


\section{RESULTS AND DISCUSSION}

The search of the databases resulted in the retrieval of 13,008 studies, with 5,110 replications across the databases. After reading of titles and abstracts, uncontrolled and randomized articles, such as review studies, randomized clinical trials, in vitro and in vivo studies performed in patients diagnosed with benign tumors were rejected, giving a total of 20 studies eligible for reading in full. After reading of articles, 14 were excluded due to differences such as administration of curcumin through oral, topical or mouthwash routes without subsequent ingestion, no access to the full study, lack of data and non-randomized studies. A schematic diagram of the search strategy is depicted in Figure 2.
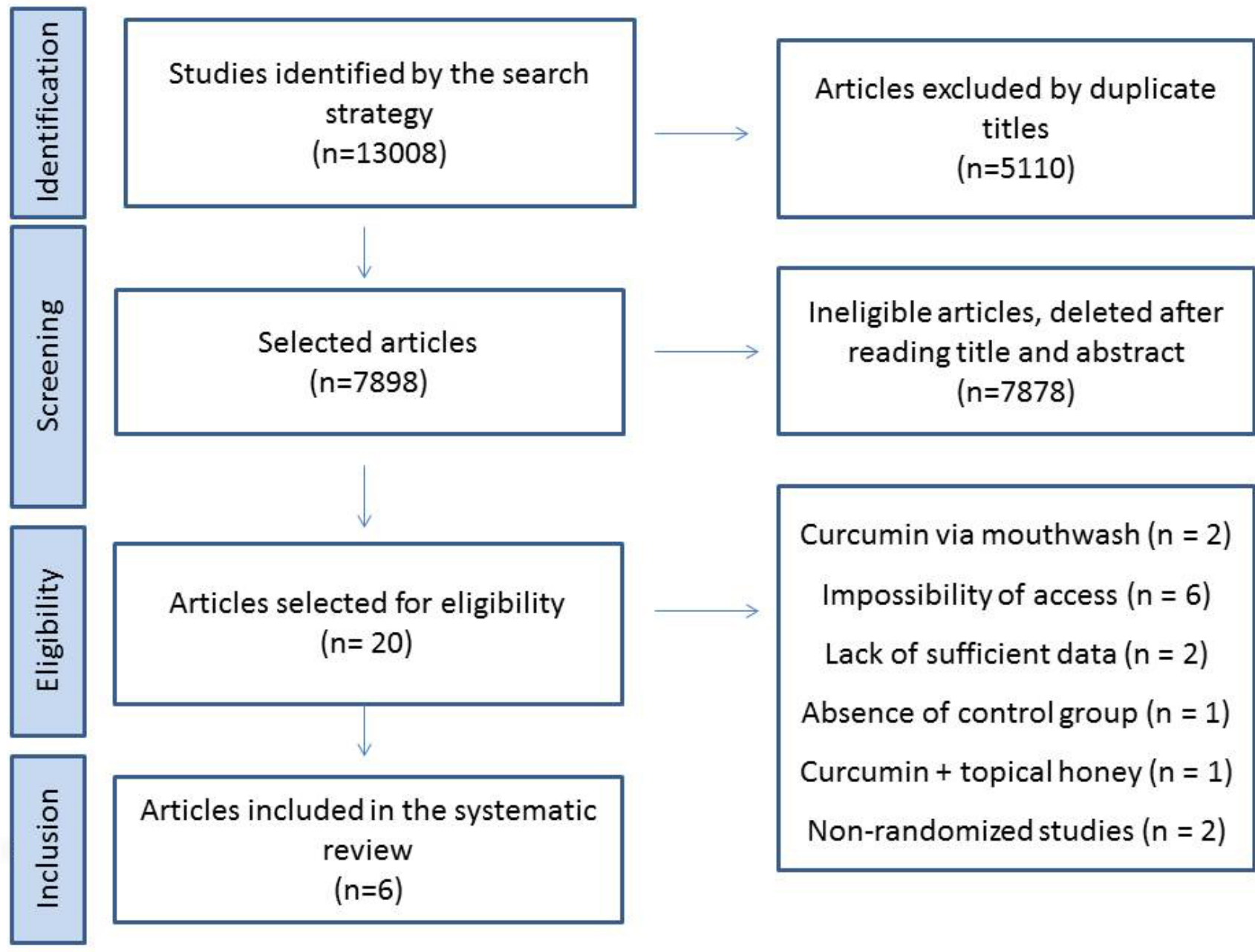

$$
\begin{aligned}
& \text { Curcumin via mouthwash }(n=2) \\
& \text { Impossibility of access }(n=6) \\
& \text { Lack of sufficient data }(n=2) \\
& \text { Absence of control group }(n=1) \\
& \text { Curcumin + topical honey }(n=1) \\
& \text { Non-randomized studies }(n=2)
\end{aligned}
$$

FIGURE 2 - PRISMA illustrative diagram of the systematic search incorporated in this evaluation.

Of the six eligible studies, three reported the effect of curcumin on anti-inflammatory profile (He et al., 2011; Panahi et al., 2014; Thomas et al., 2014), one described reduction in dermatitis after radiotherapy (Ryan et al., 2013), three showed modification of PSA (Thomas et al., 2014; Hejazi et al., 2016; Van Die et al., 2017) and one study reported an effect on the profile of antioxidant enzymes (Hejazi et al., 2016). A total of 450 adults, comprising 259 individuals in intervention groups and 191 in control groups were included. The age of participants in the studies ranged from 25 to 75 years. The main characteristics of the studies are described in Table I. 
TABLE I - Summary of characteristics of clinical trials

\begin{tabular}{|c|c|c|c|c|c|c|}
\hline $\begin{array}{l}\text { Author } \\
\text { and } \\
\text { location }\end{array}$ & $\begin{array}{c}\text { Intervention } \\
\text { duration }\end{array}$ & Population & Dose & $\begin{array}{c}\text { Type of } \\
\text { associated } \\
\text { treatment }\end{array}$ & Intervention & Outcomes \\
\hline $\begin{array}{l}\text { He et al., } \\
2011 \\
\text { USA }\end{array}$ & $\begin{array}{l}10,20 \text { and } \\
30 \text { days } \\
\text { (depending on } \\
\text { preoperative } \\
\text { period) }\end{array}$ & $\begin{array}{c}71 \text { adult } \\
\text { patients with } \\
\text { colorectal CA }\end{array}$ & $\begin{array}{l}\text { Capsules with } \\
360 \text { mg curcumin } \\
\text { 3x/day (1.08g/ } \\
\text { day curcumin) }\end{array}$ & $\begin{array}{l}\text { Radiotherapy or } \\
\text { chemotherapy } \\
\text { or combination } \\
\text { of both }\end{array}$ & $\begin{array}{l}\text { Curcumin } \\
\text { vs. control }\end{array}$ & $\begin{array}{l}\text { Body weight, TNF- } \alpha \text {, } \\
\text { P-53 protein expression, } \\
\text { pro-apoptotic gene } \\
\text { levels, and apoptosis } \\
\text { death repressor and } \\
\text { inducer proteins. }\end{array}$ \\
\hline
\end{tabular}

\begin{tabular}{|c|c|c|c|c|c|c|}
\hline $\begin{array}{l}\text { Hejazi et } \\
\text { al., } 2016 \\
\text { Iran }\end{array}$ & $\begin{array}{l}\text { One week } \\
\text { before start of } \\
\text { radiotherapy } \\
\text { until its } \\
\text { conclusion } \\
\text { (2 years) }\end{array}$ & $\begin{array}{l}45 \text { patients } \\
\text { with prostate } \\
\text { CA without } \\
\text { metastasis. }\end{array}$ & $\begin{array}{c}\text { Capsules of } \\
500 \mathrm{mg} \text { of BCM95, } \\
\text { Biocurcumin } 6 \mathrm{x} / \\
\text { day (3g/day of } \\
\text { curcumin) }\end{array}$ & $\begin{array}{l}\text { Radiation } \\
\text { therapy with } \\
74 \text { Gy dose }\end{array}$ & $\begin{array}{l}\text { Curcumin vs. } \\
\text { Control with } \\
\text { rice bran }\end{array}$ & $\begin{array}{c}\text { Body weight, PSA levels, } \\
\text { SOD, catalase, GPx. }\end{array}$ \\
\hline
\end{tabular}

\begin{tabular}{|c|c|c|c|c|c|}
\hline $\begin{array}{l}\text { Panahi et } \\
\text { al., } 2014 \\
\text { Iran }\end{array}$ & 8 weeks & $\begin{array}{c}80 \text { patients } \\
\text { diagnosed with } \\
\text { solid tumors }\end{array}$ & $\begin{array}{c}3 x 300 \mathrm{mg} \text { Meriva } \\
\text { capsules per day } \\
(180 \mathrm{mg} / \text { day } \\
\text { curcumin })\end{array}$ & $\begin{array}{l}\text { Chemotherapy } \\
\text { specific for } \\
\text { each CA type }\end{array}$ & $\begin{array}{l}\text { Curcumin } \\
\text { vs. control }\end{array}$ \\
\hline
\end{tabular}

IL-6, IL-8, calcitonin gene, TNF- $\alpha$, MCP-

1, TGF $\beta$, CRP and quality of life evaluation using the University of Washington scale

(UW-QoL).

\begin{tabular}{|c|c|c|c|c|c|c|}
\hline $\begin{array}{l}\text { Thomas et } \\
\text { al., } 2014 \\
\text { United } \\
\text { Kingdom }\end{array}$ & 6 months & $\begin{array}{l}199 \text { men with } \\
\text { prostate cancer }\end{array}$ & $\begin{array}{l}1 \text { capsule with: } \\
\text { powder of broccoli } \\
100 \mathrm{mg} \text {, turmeric } \\
\text { powder } 100 \mathrm{mg}, \\
\text { pomegranate } \\
100 \mathrm{mg} \text { and green } \\
\text { tea extract } 100 \mathrm{mg} \text {, } \\
3 x / \text { day } \\
(300 \mathrm{mg} / \text { day of } \\
\text { curcumin })\end{array}$ & No information & $\begin{array}{l}\text { Curcumin, } \\
\text { Broccoli, } \\
\text { Pomegranate } \\
\text { and Green Tea } \\
\text { vs. Control } \\
\text { containing the } \\
\text { same volume } \\
\text { and anti- } \\
\text { caking agent, } \\
\text { with } 10 \mathrm{mg} \\
\text { of watercress } \\
\text { extract }\end{array}$ & Serum levels of PSA \\
\hline
\end{tabular}


TABLE I - Summary of characteristics of clinical trials

\begin{tabular}{|c|c|c|c|c|c|c|}
\hline $\begin{array}{l}\text { Author } \\
\text { and } \\
\text { location }\end{array}$ & $\begin{array}{c}\text { Intervention } \\
\text { duration }\end{array}$ & Population & Dose & $\begin{array}{c}\text { Type of } \\
\text { associated } \\
\text { treatment }\end{array}$ & Intervention & Outcomes \\
\hline $\begin{array}{l}\text { Van Die et } \\
\text { al., } 2017 \\
\text { Australia }\end{array}$ & 12 weeks & $\begin{array}{c}20 \text { adult } \\
\text { patients with } \\
\text { prostate CA }\end{array}$ & $\begin{array}{c}2 \text { capsules, } 2 x / \text { day } \\
\text { of curcumin }(400 \\
\mathrm{mg} / \mathrm{d}) ; \text { resveratrol } \\
(120 \mathrm{mg} / \mathrm{d}) ; \text { green } \\
\text { tea }(400 \mathrm{mg} / \mathrm{d}) ; \\
\text { broccoli }(8 \mathrm{~g} / \mathrm{d}) .\end{array}$ & $\begin{array}{l}\text { Surgery, } \\
\text { radiotherapy } \\
\text { or both }\end{array}$ & $\begin{array}{c}\text { Curcumin, } \\
\text { Resveratrol, } \\
\text { Green Tea } \\
\text { and Broccoli } \\
\text { vs. Control } \\
\text { containing } \\
\text { oats }\end{array}$ & Serum levels of PSA \\
\hline
\end{tabular}

Legend: Interleukin 6 (IL-6); Interleukin 8 (IL-8); Interleukin 10 (IL-10); Interleukin 1 (IL-1); IL-1 receptor antagonist (IL1RA); tumor necrosis factor alpha (TNF- $\alpha$ ); cyclooxygenase-2 (COX-2); phosphorylated signal transducer and activator of transcription 3 (pSTAT3); Symptom Inventory (SI); -Short Form McGill Pain Questionnaire (SF-MPQ); Radiation Dermatitis Severity (RDS) score; Monocyte Chemotactic Protein-1 (MCP-1); transforming growth factor- $\beta$ (TGF $\beta$ ); C-reactive protein (CRP); superoxide dismutase (SOD); glutathione peroxidase (GPx); prostate specific antigen (PSA); insulin-like growth factor 1 (IGF-1); derivatives of reactive oxygen metabolites (D-ROMs).

Four studies used curcumin alone (He et al., 2011; Hejazi et al., 2016; Panahi et al., 2014; Ryan et al., 2013), whereas in two studies curcumin was associated with other nutrients (Van Die et al., 2017; Thomas et al., 2014).
Three studies used curcumin in commercially available capsules with standardized formulations (Hejazi et al., 2016; Panahi et al., 2004; Ryan et al., 2013). The main results of these studies are described in Table II.

TABLE II - Summary of main results of clinical trials

\begin{tabular}{llll}
\hline $\begin{array}{l}\text { Study and } \\
\text { year }\end{array}$ & $\begin{array}{l}\text { Outcomes } \\
\text { of interest }\end{array}$ & Main results & Adverse effects
\end{tabular}

He et al.,
2011

Statistically significant reduction in serum TNF alpha levels observed in patients in the curcumin group, but not in those treated with placebo. Administration with curcumin induced apoptosis, increased p53 expression and reduced Bax and Bcl-2 levels in colorectal CA cells.
Reported occurrence of diarrhea in 2 patients, one in the intervention group and one in the placebo group.

\begin{tabular}{|c|c|c|c|}
\hline $\begin{array}{l}\text { Ryan et al., } \\
2013\end{array}$ & $\begin{array}{c}\text { Decrease in } \\
\text { severity of } \\
\text { dermatitis }\end{array}$ & $\begin{array}{l}\text { Significant decrease in scores on RDS scale in } \\
\text { curcumin group compared to placebo, with decrease } \\
\text { after the fourth week. In addition, lower number of } \\
\text { patients in the curcumin group had moist desquamation } \\
\text { compared to the placebo group, however, with no } \\
\text { change in the skin redness. There was no significant } \\
\text { difference between groups regarding local pain. }\end{array}$ & $\begin{array}{l}\text { The Symptom Inventory } \\
\text { questionnaire was used, } \\
\text { where no statistical difference } \\
\text { was observed between the } \\
\text { curcumin and placebo groups } \\
\text { for } 17 \text { symptoms present } \\
\text { in the questionnaire. }\end{array}$ \\
\hline
\end{tabular}


TABLE II - Summary of main results of clinical trials

$\begin{array}{llll}\begin{array}{l}\text { Study and } \\ \text { year }\end{array} & \begin{array}{l}\text { Outcomes } \\ \text { of interest }\end{array} & \text { Main results } & \text { Adverse effects }\end{array}$

Statistically significant reduction in serum levels of TNF- $\alpha$, IL- 6 and IL- 8 in both groups. Reductions in TNF- $\alpha$ and IL-6 were significantly higher in the curcuminoid group Panahi et al., IL-6, IL-8, 2014 TNF- $\alpha$ compared to control group. In contrast, IL-8 reduction was significantly higher in the placebo group, changes in serum IL-8 levels were a predictor of quality of life in the placebo group. In both groups, reduction in TNF- $\alpha$ levels were predictors of quality and life improvement.
Eight patients reported mild gastrointestinal effects.

However, there was no abandonment as a result of adverse reactions to treatment.
Thomas et al., 2014

PSA, CRP
There was a significant reduction in serum PSA levels in the intervention group compared to placebo. The mean percentage of PSA increased more slowly in the supplemented group, compared to placebo, a result with statistical significance. An analysis of the subgroup of men under active surveillance also revealed that after the intervention, mean PSA fell while the placebo increased, with a significant difference. For the subgroup of men managed with watchful waiting, PSA had a smaller increase in the intervention group than the placebo group, with statistical difference. Regarding CRP levels, there were no significant differences at the beginning or end of the study between the supplement and control groups.
There were adverse effects such as diarrhea, agitation, tremors and insomnia in both groups, but with no statistical difference.
There was a statistically significant increase in total antioxidant capacity and a reduction in SOD activity in the curcumin group. PSA levels were significantly reduced in both groups. There was a decrease in catalase activity, but not statistically significant. There were no changes in GPx activity.
No adverse effects were reported in the two groups.
There was variation in serum PSA levels for both groups. The supplemented group showed a nonsignificant improvement in PSA values, whereas the placebo group showed no change.
Adverse events were reported in both groups, with no statistical difference, such as "heartburn", and one case of restlessness that persisted throughout the treatment phase. Two men experienced a nocturia increase initially, but this symptom was resolved.
In this review, five studies showed a beneficial effect in the form of improvements in biochemical and clinical indicators among patients with several CA types after curcumin use, such as reductions in IL- 6 , TNF- $\alpha$, hs-CRP, and an increase in TAC and improvement in the degree of dermatitis associated with radiotherapy treatment (Panahi et al., 2011; Hejazi et al., 2014; Ryan et al., 2013). Four studies (Panahi et al., 2014; Van Die et al., 2017; He et al, 
Taise Andrade da Anunciação, Laís Spindola Garcez, Emile Miranda Pereira, Valterlinda Alves de Oliveira Queiroz, Priscila Ribas de Farias Costa, Lucivalda Pereira Magalhães de Oliveira

2011; Thomas et al., 2014) showed limited adverse effects and good tolerance to the use of curcumin; data which corroborates those of other similar studies (Imran et al., 2016; Rezaee et al., 2017).

The clinical trial conducted by Panahi et al. (2014) showed a reduction in IL-6 levels in both groups $(1.55$ to $0.61, \mathrm{p}<0.001$ in curcumin group vs 1.57 to $1.31, \mathrm{p}<0.001$ in placebo group), where this reduction was significantly higher in the curcuminoid group compared to the control group ( $\mathrm{p}<0.001)$. There was also a reduction in IL-8 in the curcumin group (21.64 to $19.78 ; \mathrm{p}=0.001)$ vs placebo group (26.23 to 21.38; $\mathrm{p}<0.001$ ); but levels were significantly higher in the placebo group $(\mathrm{p}=0.012)$. There were no differences between individuals who received radiotherapy or not, or in type of CA ( $p>0.05)$.

Ultra-sensitive CRP levels (hs-CRP) showed a significant decrease in both curcumin (6.96 to 4.63, p $<0.001)$ and placebo (8.54 to $7.92, \mathrm{p}=0.039)$ groups. There were also significant reductions in serum TNF- $\alpha$ concentrations ( 28.03 to $15.74, \mathrm{p}<0.001)$ in the curcumin vs placebo group (27.05 to $25.33, \mathrm{p}=0.039$ ), with greater decrease in patients supplemented with curcuminoids compared to placebo (TNF- $\alpha \mathrm{p}<0.001$ and hs-CRP $p$ $<0.001$ ) (Panahi et al., 2014). It is noteworthy that in this study all patients were undergoing chemotherapy and one of the exclusion criteria was exacerbation of the disease to an uncontrollable level.

In this study by Panahi et al. (2014), the quality of life of patients diagnosed with solid tumors supplemented with curcumin was positively correlated with the reduction in hs-CRP $(r=0.25, p=0.081)$ and negatively with changes in IL-6 levels $(r=-0.53, p=0.001)$. Among the patients in the placebo group, there was a negative correlation of quality of life with reduction in TNF- $\alpha(\mathrm{r}=-0.37, \mathrm{p}=$ $0.020)$ and IL-8 $(\mathrm{r}=-0.68, \mathrm{p}<0.001)$ (Panahi et al., 2014).

Despite the low dose of curcumin used in the study by Panahi et al. (2014) (180 mg/day) and short intervention time, an improvement in the quality of life of patients diagnosed with solid tumors was observed, accompanied by a significant reduction in serum levels of inflammatory mediators (IL-6, TNF $\alpha$ and hs-CRP). The author attributes the clinical efficacy of adjunctive therapy with curcumin to co-administration of phosphatidylcholine (lecithin) and curcuminoids, shown by several in vitro studies to increase bioavailability of this phytochemical (Gupta et al., 2013; Shehzad et al., 2010). Curcumin is one of the greatest inhibitors of NF- $\mathrm{KB}$ and is known to modulate various biomarkers of inflammation, oxidative stress, apoptosis and tumor growth in patients with CA. A limitation of the study by Panahi et al. (2014) was that individuals in the curcuminoid group had a significantly lower quality of life score at baseline compared to the placebo group, which may have reflected a more compromised health status and the possibility of greater response to treatment in these patients (Panahi et al., 2014).

In the study by He et al. (2011), there was a significant reduction in TNF- $\alpha$ percentage levels in patients treated with curcumin after 10 days of treatment $(\mathrm{p}<0.05)$. The results showed a negative correlation between body weight gain of patients with colorectal CA in curcumin capsule use and decreased serum levels of TNF- $\alpha(r=-0.40 p<0.05)$.

The study of He et al. (2011) also showed a reduction in serum TNF levels and significant improvement in weight loss among adult patients with colorectal cancer after supplementation with $1.08 \mathrm{~g} /$ day of curcumin. The hypothesis described by the researchers was that curcumin can increase the apoptosis of cancer cells and positively regulates the p53 molecule (He et al., 2011).

It is known that chronic inflammation is present in patients with $\mathrm{CA}$ and might be involved in the carcinogenic process, inducing changes in CA-related genes and post-translational modification in signaling proteins involved in the cell cycle, DNA repair and cell apoptosis. Inflammation also produces several symptoms associated with CA progression, such as weight loss and impaired immunity (Hanahan, Weinberg, 2011; Eiro, Vizoso, 2012). Curcumin is considered one of the major inhibitors of NF- $\mathrm{KB}$ and is known to modulate various biomarkers of inflammation, oxidative stress and apoptosis (Panda et al., 2017; Imran et al., 2016).

Total antioxidant capacity (TAC) and antioxidant enzymes were determined in the study by Hejazi et al. (2016) one week before the start of radiotherapy and again three months after curcumin treatment of patients with prostate cancer. The patients in the curcumin and placebo groups did not differ significantly in relation to the intake of antioxidant or pro-oxidant foods. After the intervention period, TAC had increased from $10.7 \mathrm{U} / \mathrm{L}$ to $12.8 \mathrm{U} / \mathrm{L}$ (p $<0.001)$ in the curcumin group. Patients in the placebo group also exhibited increased TAC, but without statistical significance. The post-treatment increase in TAC was higher in the curcumin group (12.8 vs 10.6, $\mathrm{p}=0.014$ ), suggesting that curcumin may be an antioxidant agent (Hejazi et al., 2016).

SOD activity decreased from $226 \mathrm{U} / \mathrm{L}$ to $189.4 \mathrm{U} / \mathrm{L}$ $(p=0.018)$ in the curcumin group, whereas no significant change was observed in the placebo group (Hejazi et al., 2016). 
In some studies involving animal and in vitro models, the activity of enzymes such as SOD, catalase, and GPx increased after curcumin supplementation (Huang et al., 2012; Tawfik et al., 2013). However, in the study by Hejazi et al. (2016), curcumin did not increase catalase or GPx activity, and reduced SOD activity; thus, according to the authors, this seems to suggest that, in the presence of curcumin, SOD expression may not necessarily increase (Hejazi et al., 2016).

In a clinical study by Thomas et al. (2014) evaluating the effect of the use of a dietary supplement on the progression of PSA in men with prostate cancer, in the group supplemented with polyphenols extracted from curcumin, broccoli, pomegranate and green tea, PSA increased from 6.50 to $6.81 \mathrm{ugl}$, whereas in the placebo group, levels increased from 6.50 to $10.98 \mathrm{ugl}$. The PSA increase was lower in the supplement group compared to the control group (6.81 vs $10.98, \mathrm{p}=0.0008)$ (Thomas et al., 2014).

The percentage of individuals with lower or the same PSA value at the end of the trial was $46 \%$ in the supplement group and $14 \%$ in the control group, a statistically significant difference $(p=0.000010)$. A subanalysis of 121 patients in this study, together with active surveillance showed that mean PSA decreased $0.14 \%$ in the supplemented group, but increased by $46.98 \%$ $(p=0.001)$ in the control group. Analysis of men followedup with watchful waiting ( $\mathrm{n}=78$ ), a form of symptomguided treatment, showed that PSA increased by $8.78 \%$ in the supplement group, whereas in the placebo group, the level increased by $80.34 \%(\mathrm{p}=0.001)$. It is noteworthy that the mean levels of sex hormones were normal for both groups (Thomas et al., 2014).

The favorable effect in reducing serum PSA levels observed after capsule supplementation with broccoli powder, curcumin, pomegranate and green tea extract was found both in men with primary prostate cancer and those with disease recurrence. The authors argued that foods rich in polyphenols demonstrated anti-neoplastic effects involving angiogenesis, apoptosis and cell proliferation in laboratory models (Thomas et al., 2014). It was emphasized that patient characteristics were well balanced and the study had sufficient numbers to ensure adequate statistical power. However, the intervention period (6 months) was short and the study design included men with primary disease besides those who relapsed after radical treatments (Thomas et al., 2014).

However, another study failed to demonstrate a significant reduction in PSA after intervention with $500 \mathrm{mg}$ of curcumin three months after completion of radiotherapy (12.98 to $0.12, \mathrm{p}=0.78$ ) (Hejazi et al., 2016). Similarly, the study by Van Die et al. (2017) found no significant changes in PSA levels among supplemented patients after capsule intervention with phenolic compounds extracted from turmeric, resveratrol, green tea and propolis or in the placebo group (Van Die et al., 2017). Notably, the study was not designed to detect effects on change in serum PSA levels. Among the limitations, it should be noted that the PSA tests were not always performed in the same laboratory, and the baseline biochemical data were collected during screening, and not repeated at the time of randomization.

A study of women receiving radiotherapy treatment for CA of the breast evaluated the degree of dermatitis using the RDS (Radiation Dermatitis Severity) scale. The group supplemented with curcumin showed a significant reduction in the degree of dermatitis compared to placebo $(p=0.008)$. Mean RDS scores for patients treated with curcumin were 0.8 lower than those in the placebo group. It was observed that $28.6 \%$ of patients treated with curcumin had moist desquamation after radiotherapy, while $87.5 \%$ of patients in the control group experienced this adverse effect $(\mathrm{p}=0.002)$ (Ryan et al., 2013).

There were no statistically significant differences between treatment groups in terms of intensity of perceived pain, sensory pain, or scores on the McGill Pain Questionnaire subscale (Ryan et al., 2013). In the evaluation related to individual pain, the curcumin group differed significantly from the placebo group ( $p$ $\leq 0.021$ ), with lower pain for the sensory descriptors of "corroding" and "painful" pain. The authors also observed that women in the curcumin group had lower "depressed" status compared to placebo $(\mathrm{p}=0.023)$ (Ryan et al., 2013). The authors concluded that administration of oral curcumin significantly reduced the severity of radiation dermatitis and moist desquamation, although did not reduce erythema. Thus, curcumin was ineffective for reducing the severity of dermatitis in women undergoing total mastectomy prior to the commencement of radiation therapy (Ryan et al., 2013). It is important to point out that a cream gel containing hydrocortisone was supplied to patients of both groups. Curcumin has previously been studied for its radiomodulatory properties, protecting noncancerous tumor cells with radiosensitization (Amalraj et al., 2017).

In the study by Thomas et al. (2014), 24\% of the individuals presented adverse events in the supplement group and 34\% in the control, but without significant 
Taise Andrade da Anunciação, Laís Spindola Garcez, Emile Miranda Pereira, Valterlinda Alves de Oliveira Queiroz, Priscila Ribas de Farias Costa, Lucivalda Pereira Magalhães de Oliveira

difference between the groups $(\mathrm{p}=0.14)$. Among these events, diarrhea, flatulence, and abdominal distension occurred in $15.5 \%$ of the supplement group compared with $7.5 \%$ of the patients in the control group $(\mathrm{p}=0.11)$. In a study carried out by Panahi et al. (2014), 16\% of patients in the supplement group experienced adverse events such as worsening of urinary flow, renal function decline and non-specific disease, whereas $22 \%$ of subjects in the placebo group had these symptoms, with no statistical difference. Despite these adverse events reported, no patient discontinuation was recorded in this protocol (Panahi et al., 2014). In another study, 10 patients administered $360 \mathrm{mg}$ of curcumin or placebo, experienced diarrhea with no statistical difference between groups ( $\mathrm{p}>$ 0.05) (He et al., 2011).

In the study conducted by Van Die et al. (2017), 12 adverse events were identified among patients supplemented with curcumin, resveratrol, green tea and broccoli. The main symptoms were burns, restlessness and increased nocturia, classified by participants as mild, and heartburn, classified as moderate. There were also 13 adverse events among individuals in the placebo group, such as flatulence and constipation, with no statistically significant difference in severity of symptoms between groups ( $\mathrm{p}=0.702)$ (Van Die et al., 2017).

It is important to note the widely divergent factors among studies included in this review, where only a small number of clinical trials had well-controlled methodologies, adequate sample size, representativeness of the study population, appropriate intervention time and appropriate statistical analyses. This can directly impact both the positive results and controversial findings, representing an important limitation for conclusions on this topic.

A review of studies has shown that curcumin compound is safe when ingested in daily doses of up to $12 \mathrm{~g}$, while toxicity at higher levels has not been established (Imran et al., 2016; Rezaee et al., 2017). In the present review, the dose of curcumin among the studies ranged from $180 \mathrm{mg}$ to $3 \mathrm{~g}$ daily and frequency of ingestion was one to six times a day, used in different formulations, alone or in association with other nutrients. Three studies used curcumin in commercially available capsules with standard formulations (Hejazi et al., 2016; Panahi et al., 2014; Ryan et al., 2013) containing specific information on the amounts and proportions of the curcuminoids present in the formulations. These factors may justify the benefits described in these studies since the addition of curcumin to other agents has been associated with an improvement in its bioavailability. Co-administration of curcuminoids with phosphatidylcholine has been associated with improved bioavailability (Anand et al., 2007; Gupta et al., 2013; Shehzad et al., 2010).

Two studies used donated capsules, however, the authors reported no conflict of interest (Hejazi et al., 2016; Panahi et al., 2014). The data from this systematic review suggest that oral curcumin was well tolerated by the patients and the studies analyzed did not report any serious adverse effects in the intervention group, with similar side effects for both curcumin and placebo groups. The main symptoms reported were diarrhea, agitation, tremors, and insomnia, which may be confounded with symptoms associated with antineoplastic treatment. No differences were observed between curcumin supplementation in patients with combination therapy (chemotherapy and radiotherapy) or single therapy.

The present review systematically chose to analyze randomized and controlled clinical trials, considering this design the gold standard among all clinical investigation methods, since it is capable of producing scientific evidence with a lower probability of error to clarify a cause-and-effect relationship between the events (Carvalho et al., 2013).

Regarding the quality of the selected papers, in general, there was a low risk of bias in relation to the items of random sequence generation, the blinding of participants and professionals, blinding of outcome assessors, incomplete outcome data and report of a selective outcome. However, information on allocation concealment and other potential biases were unclear in the studies evaluated, which may raise some doubts about the results. Whereas a risk of bias may exist, there is insufficient information to assess whether there is a significant risk, although none of the studies evaluated were considered to be associated with a high risk of injury.

It was not possible to evaluate the publication bias of the studies included in this review, through the analysis of funnel plot and Egger test, since these analyses are recommended for meta-analyses with at least 10 studies, and are therefore not indicated for this study (Higgins et al., 2011).

Strengths of this review include the preparing of a sensitive and comprehensive search strategy without restrictions on geographic location, language, year of publication or attribution of outcome at the time of the search to increase search potential; as well as the preparation of the clinical records for data collection and extraction. We also used review articles for the manual 
checking of references and identification of possible relevant studies. However, it was not possible to perform a broad search in the gray literature. Despite contacting authors to retrieve missing data in the studies, a large number of articles were excluded.

\section{Analysis of risk of bias}

The risk of bias was assessed for randomized clinical trials according to the Cochrane Collaboration criteria for the development of systematic reviews of intervention studies (Higgins et al., 2011; Carvalho et al., 2013).

The study carried out by Thomas et al. (2014) was the only investigation classified as low risk of injuries on all evaluated items. The remaining papers were deemed as having an uncertain risk, since they had one or more answers with information that raised doubts about the results or with insufficient reporting of information, making it impossible to judge adequately.
The study of Van Die et al. (2017) had low risk for selection and friction, being classified in the final judgment as having an uncertain risk since it obtained three responses that could not be determined. The study published by He et al. (2011) had low risk on three items; generation of random sequence, blinding of participants and professionals and blinding of outcome assessors. In the study by Hejazi et al. (2016), the final judgment was classified as uncertain risk due to flaws in concealment of allocation items and other sources of evidence. In the study by Panahi et al. (2014), only the item related to data on incomplete outcomes, in the characterization of friction was considered low risk.

The article published by Ryan et al. (2013) obtained a low risk of blinding for participants and professionals, blinding of outcome assessors, incomplete outcome data, and other sources of evidence, but two responses were classified as an uncertain risk. The details of this evaluation are given in Figure 3.

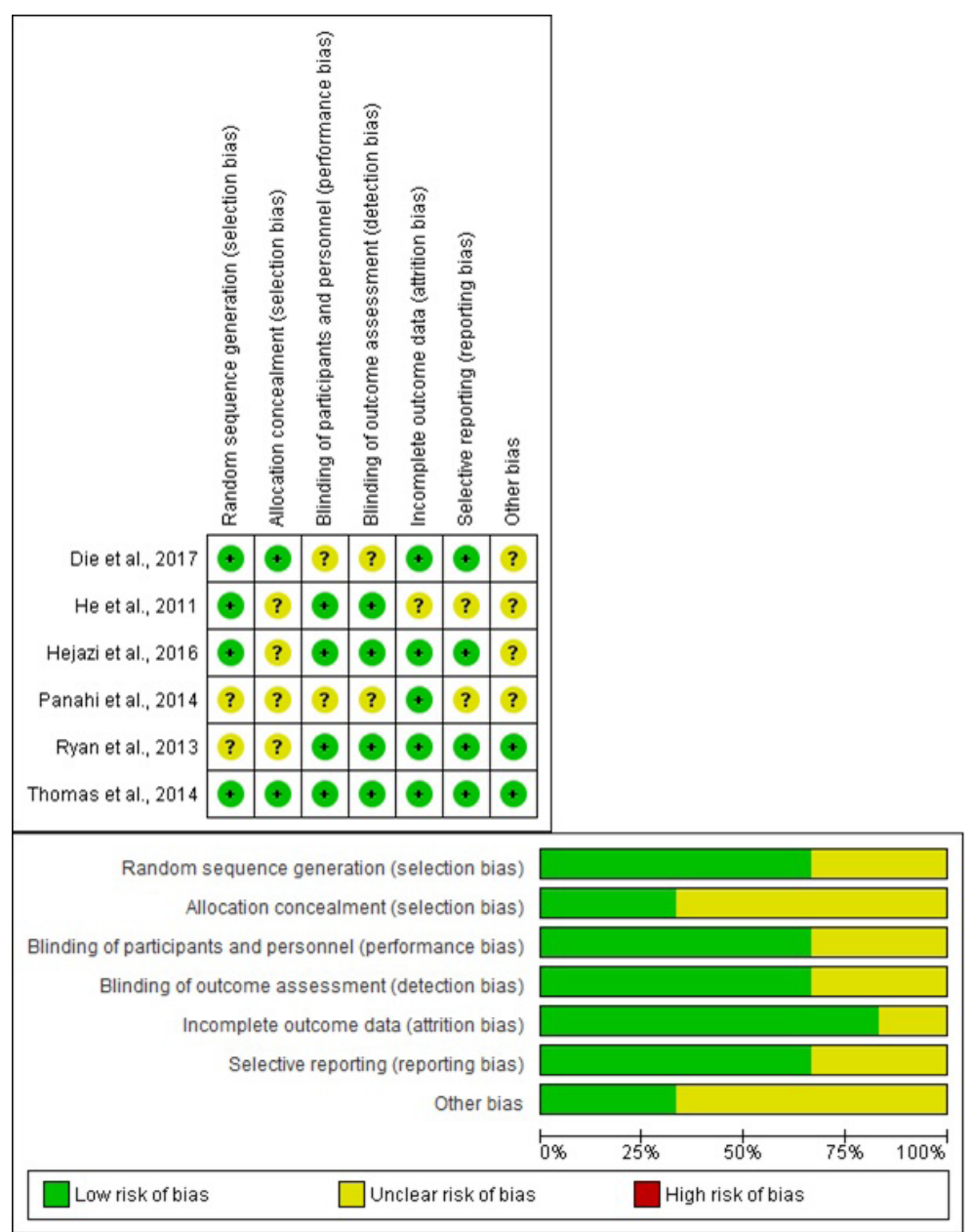

FIGURE 3 - Assessment of bias risk. (a) Bias risk summary: a review of each bias risk item for each included study. (b) Bias risk chart: a review of each bias risk item, expressed in $\%$, for all included studies. 


\section{CONCLUSION}

This systematic review, which evaluated six eligible clinical trials, demonstrated a potential benefit of curcumin supplementation in the treatment of cancer patients, specifically in the decrease of inflammatory markers, increase in total antioxidant capacity, and reduction of dermatitis severity. However, it is important to consider the great heterogeneity and methodological weakness of the studies, and that it was not possible to perform a meta-analysis of the data available in the literature. The active principle, dosage, and duration of supplementation proved important aspects, with high variability among the evaluated articles. Despite the low risk of bias found for several items, five studies were ultimately classified as having uncertain risk.

Thus, it was not possible to conclude, with the degree of scientific evidence desired, the effect of oral curcumin supplementation in the adjuvant treatment of cancer patients. There is in sufficient evidence for consensus on the use of curcumin in clinical practice or on the dose and supplementation time needed to confer benefits to cancer patients. Despite the growing interest in the use of this phytochemical as a co-adjuvant in the treatment of cancer patients, further clinical trials with more consistent methodological designs are required.

Studies with bioavailable formulations should be conducted to elucidate the relationship between curcumin and its pharmacological activity in neoplastic cells. Such research can yield more consolidated scientific evidence allowing greater safety in the indication and dosage of this phytochemical, thereby helping to improve cancer treatment and quality of life of these patients.

\section{REFERENCES}

Adhvaryu MR., Reddy N, Vakharia BC. Prevention of hepatotoxicity due to anti tuberculosis treatment: a novel integrative approach. World J Gastroenterol. 2008;14(30):4753-62.

Amalraj A., Pius A., Gopi A., Gopi S. Biological activities of curcuminoids, other biomolecules from turmeric and their derivatives - A review. Journal of Traditional and Complementary Medicine. 2017;(7):205-233.

Aggarwal BB, Surh YJ, Shishodia S. The molecular targets and therapeutic uses of curcumin in health and disease. Adv Exp Med Biol. 2007. Springer publication.
Anand P, Kunnumakkara AB, Newman RA., Aggarwal BB. Bioavailability of curcumin: problems and promises. Mol Pharm. 2007;4(6):807-18.

Belcaro G, Cesarone MR, Dugall M, Pellegrini L, Ledda A, Grossi MG, et al. Product-evaluation registry of Meriva(R), a curcumin-phosphatidylcholine complex, for the complementary management of osteoarthritis. Panminerva Med. 2010;52(2Suppl 1):55-62.

Biswas J, Sinha D, Mukherjee S, Roy S, Siddiqi M, Roy M. Curcumin protects DNA damage in a chronically arsenicexposed population of West Bengal. Hum Exp Toxicol. 2010; 29 (6):513-24.

Boyanapalli SS, Tony Kong AN. "Curcumin, the King of Spices": Epigenetic Regulatory Mechanisms in the Prevention of Cancer, Neurological, and Inflammatory Diseases. Curr Pharmacol Rep. 2015;1(2):129-139.

Brasil. Ministério da Saúde. Secretaria de Ciência, Tecnologia e Insumos Estratégicos. Departamento de Ciência e Tecnologia. 2012. Diretrizes metodológicas: elaboração de revisão sistemática e metanálise de ensaios clínicos randomizados. Brasília: Editora do Ministério da Saúde.

Carvalho APV, Silva V, Grande AJ. Avaliação do risco de viés de ensaios clínicos randomizados pela ferramenta de colaboração Cochrane. Revista Diagnóstico e Tratamento. 2013;18:38-44.

Dhillon N, Aggarwal BB, Newman RA, Wolff RA, Kunnumakkara AB, Abbruzzese JL, et al.. Phase II trial of curcumin in patients with advanced pancreatic cancer. Clin Cancer Res. 2008;14(14):4491-9.

Durgaprasad S, Pai CG, Vasanthkumar Alvres JF, Namitha S. A pilot study of the antioxidant effect of curcumin in tropical pancreatitis. Indian J Med Res. 2005;122(4):315-8.

Eiró N, Vizoso FJ. Inflammation and cancer. World $\mathbf{J}$ Gastrointest Surg. 2012;274(3):62-72.

Ferlay J, Soerjomataram I, Dikshit R, Eser S, Mathers C, Rebelo M, et al. Cancer incidence and mortality worldwide: sources, methods and major patterns in GLOBOCAN 2012. Int J Cancer. 2015;136(5):E359-E386.

Golombick T, Diamond TH, Badmaev V, Manoharan A, Ramakrishna $\mathrm{R}$. The potential role of curcumin in patients with monoclonal gammopathy of undefined significanceits effect on paraproteinemia and the urinary N-telopeptide of type I collagen bone turnover marker. Clin Cancer Res. 2009;15(18):5917-22. 
Gupta SC, Patchva S, Aggarwal BB. Therapeutic roles of curcumin: lessons learned from clinical trials. AAPS J. 2013;15(1):195-218.

Hanahan D, Weinberg RA. Hallmarks of cancer: the next generation. Cell. 2011;144(5):646-74.

He ZY, Shi CB, Wen H, Li FL, Wang BL, Wang J. Upregulation of p53 expression in patients with colorectal cancer by administration of curcumin. Cancer Invest. 2011;29(3):20813.

Hejazi J, Rastmanesh R, Taleban FA, Molana SH, Hejazi E, Ehtejab G, et al. Effect of Curcumin Supplementation During Radiotherapy on Oxidative Status of Patients with Prostate Cancer: A Double Blinded, Randomized, Placebo-Controlled Study. Nutr Cancer. 2016;68(1):77-85.

Higgins J, Green S, Cumpston M, Chandler J. Cochrane handbook for systematic reviews of interventions [Internet]. Version 5.1.0. 2011. Oxford: Cochrane Collaboration. Available from www.cochrane-handbook.org.

Huang X, Song C, Zhong C, Wang F. Research progress in the radioprotective effect of superoxide dismutase. Drug Discov Ther. 2012;6:169-177.

Ide H, Tokiwa S, Sakamaki K, Nishio K, Isotani S, Muto S. Combined inhibitory effects of soy isoflavones and curcumin on the production of prostate-specific antigen. Prostate. 2010;70(10):1127-33.

Imran M, Ullah A, Saeed F, Nadeem M, Arshad MU, Suleria HAR. Cucurmin, anticancer, \& antitumor perspectives: A comprehensive review. Crit Rev Food Sci Nutr. 2016;22:1-23.

Kim SG, Veena MS, Basak SK, Han E, Tajima T, Gjertson DW. Curcumin treatment suppresses IKKbeta kinase activity of salivary cells of patients with head and neck cancer: a pilot study. Clin Cancer Res. 2011;17(18):5953-61.

Kunnumakkara AB, Bordoloi D, Padmavathi G, Monisha J, Roy NK, Prasad S. Curcumin, the golden nutraceutical: multitargeting for multiple chronic diseases. Br J Pharmacol. 2017;174(11):1325-1348.

Moher D, Liberati A, Tetzlaff J, Altman DG. PRISMA Group. Preferred reporting items for systematic reviews and metaanalyses: the PRISMA statement. BMJ. 2009;339:b2535.

Panahi Y, Saadat A, Beiraghdar F, Sahebkar A. Adjuvant therapy with bioavailability-boosted curcuminoids suppresses systemic inflammation and improves quality of life in patients with solid tumors: a randomized double-blind placebo-controlled trial. Phytother Res. 2014;28(10):1461-7.
Panda AK, Chakraborty D, Sarkar I, Khan T, Gaurisankar SA. New insights into therapeutic activity and anticancer properties of curcumin. Journal of Experimental Pharmacology 2017;9:31-45.

Remely M, Lovrecic L, Garza AL, Migliore L, Peterlin B, Milagro FI, et al. Therapeutic perspectives of epigenetically active nutrients. Br J Pharmacol. 2015;172:2756-68.

Rezaee R, Momtazi AA, Monemi A, Sahebkar A. Curcumin: a potentially powerful tool to reverse cisplatin-induced toxicity. Pharmacol Res. 2017;117:218-227.

Ryan JL, Heckler CE, Ling M, Katz A, Williams JP, Pentland AP, et al. Curcumin for radiation dermatitis: a randomized, double-blind, placebo-controlled clinical trial of thirty breast cancer patients. Radiat Res. 2013;180(1):34-43.

Sahebkar A, Mohammadi A, Atabati A, Rahiman S, Tavallaie $\mathrm{S}$, Iranshahi M.et al. Curcuminoids modulate pro-oxidantantioxidant balance but not the immune response to heat shock protein 27 and oxidized LDL in obese individuals. Phytother Res. 2013;27(12):1883-1888.

Shehzad A,Wahid F, Lee YS. Curcumin in cancer chemoprevention: molecular targets, pharmacokinetics, bioavailability, and clinical trials. Arch Pharm (Weinheim). 2010;343:489-499.

Shoskes D, Lapierre C, Cruz-Correa M, Muruve N, Rosario R, Fromkin B, et al. Beneficial effects of the bioflavonoids curcumin and quercetin on early function in cadaveric renal transplantation: a randomized placebo controlled trial. Transplantation. 2005;80(11):1556-9.

Tachibana H. Green tea polyphenol sensing. Proc. Jpn Acad. 2011;87(3):66-80.

Tawfik SS, Abouelella AM, Shahein YE. Curcumin protection activities against gamma-Rays-induced molecular and biochemical lesions. BMC Res Notes. 2013;6:375.

Tawfik SS, Abouelella AM, Shahein YE. Curcumin protection activities against gamma-Rays-induced molecular and biochemical lesions. BMC Res Notes. 2013;21(6):375.

Thomas R, Williams M, Sharma H, Chaudry A, Bellamy P. A double-blind, placebo-controlled randomised trial evaluating the effect of a polyphenol-rich whole food supplement on PSA progression in men with prostate cancer--the U.K. NCRN Pomi-T study. Prostate Cancer Prostatic Dis. 2014;17(2):180-6.

Vadhan-Raj S, Weber D, Wang M, Giralt S, Alexanian R, Thomas $\mathrm{S}$, et al. Curcumin downregulates NF-KB and related genes in patients with multiple myeloma: results of a phase $1 / 2$ study. Blood. 2007;110(11):357. 
Taise Andrade da Anunciação, Laís Spindola Garcez, Emile Miranda Pereira, Valterlinda Alves de Oliveira Queiroz, Priscila Ribas de Farias Costa, Lucivalda Pereira Magalhães de Oliveira

Van Die MDV, Williams SG, Emery J, Bone KM, Taylor JM, Lusk E, et al. A Placebo-Controlled Double-Blinded Randomized Pilot Study of Combination Phytotherapy in Biochemically Recurrent Prostate Cancer. Prostate. 2017;77(7):765-775.

Received for publication on $02^{\text {nd }}$ December 2018 Accepted for publication on $18^{\text {th }}$ April 2019 